\title{
Study of early cholecystectomy for mild and moderate acute cholecystitis as per Tokyo Guidelines
}

\author{
Mintu Mohan Nandi', Shib Shankar Kuiri², Yash Sharma ${ }^{3}$, Purushottam \\ Kumar $^{4}$, Goutam Ghosh ${ }^{5}$,Nilay Mandal ${ }^{6}$ \\ ${ }^{1,2}$ Assistant Professor, ${ }^{3}$ Junior Resident, ${ }^{6}$ Associate Professor, Department of General Surgery, B.S. Medical College, \\ West Bengal, ${ }^{4}$ Senior Resident, Department of General Surgery, AlIMS, Patna, ${ }^{5}$ Professor and Head, Department of \\ General Surgery, RG Kar Medical College, Kolkata, West Bengal
}

\section{A B S T R A C T}

Background: According to Tokyo Guidelines, 2007 operative management of acute cholangitis and cholecystitis to be administered earlier with preference of laparoscopic cholecystectomy over conventional open cholecystectomy. Aims and Objectives: This study was done to compare conventional cholecystectomy and laparoscopic cholecystectomy with respect to duration of operation, post operative recovery, analgesic requirement, complications encountered, duration of hospitalization, and patient satisfaction.Materials and Methods: A prospective randomized trial of 50 patients conducted at B.S.M.C.H, Bankura from January 2013 to July 2014, who admitted with a diagnosis of acute calculous cholecystitis, were randomized to undergo open and laparoscopic cholecystectomy with 25 patients in each group. Result: The commonest presenting complaint in both the groups was pain in the right upper quadrant followed by vomiting and dyspepsia. The duration of laparoscopic method was significantly more than open method (median $120 \mathrm{~min} \mathrm{v/s}$ $90 \mathrm{~min}$ respectively). The duration of pain and analgesic, antibiotic requirement was less in laparoscopic group compared to open group. The intra operative complications were more for the laparoscopic procedure. Wound infection was seen in none of laparoscopic patient but only in 2 patients of open procedure. Two patients of laparoscopic group required conversion to open procedure. The postoperative compliance is better in laparoscopic patients compared to open patients and hospital stay is also significantly less. Conclusion: The laparoscopic procedure was costly compared to open procedure. But this difference was overcome by the other costs incurred in postoperative period of open procedure. The laparoscopic procedure offered better cosmetic compared to open method.

Access this article online

Website:

http://nepjol.info/index.php/AJMS DOI: 10.3126/ajms.v9i2.19188 E-ISSN: 2091-0576

P-ISSN: 2467-9100

Key words: Acute cholecystitis, Early laparoscopic cholecystectomy, Better outcome.

\section{INTRODUCTION}

Guidelines for the management of acute cholangitis and cholecystitis were published in Japan, ahead of the rest of the world, in September, 2005. An international conference was subsequently held in Tokyo, and the Tokyo Guidelines for the Management of Acute Cholangitis and Cholecystitis were adopted as international guidelines in January, 2007.According to these guidelines, "Cholecystectomy is preferable early after admission", and "Laparoscopic cholecystectomy is preferable to open cholecystectomy " for mild and moderate acute cholecystitis.

\section{MATERIALS AND METHODS}

The study was carried out at Bankura Sammilani Medical College \& Hospital, West Bengal since January 2013 to July 2014. 50 patients with mild and moderate ie Grade I(no organ dysfunction or criteria for moderate/severe acute cholecystitis) \& II(WBC $>18.000 / \mathrm{mm}^{3}$, palpable tenderness 
in the right upper abdominal quadrant, duration $>72$ hours, marked local inflammation) respectively had undergone early cholecystectomy. Severe ie Grade III acute cholecystitis (with one or more organ dysfunction), unwilling patients, associated with co-morbid conditions (valvular heart diseases, malignancy, cirrhosis, metabolic liver disease, etc.), acute hepatitis, chronic cholecystitis, extreme of ages, associated with pregnancy were excluded from the study.

\section{Study design}

Prospective randomized control trial.

\section{Parameters dtudied}

1. Clinical status: Surface Temperature, Pulse Rate, jaundice, Right hypochondrium mass/pain/tenderness (Murphy's sign)

2. Blood Investigations: especially TLC,DLC,LFT

3. USG of Whole abdomen with special focus on Hepatobiliary system

4. Length of hospital stay

\section{Study tools}

1. Bed Head Tickets (BHT),

2. USG Reports,

3. Blood reports,

4. Laparoscopic instruments

\section{Study technique}

Fifty patients from various parts of Bankura and adjoining areas, admitted with acute cholecystitis in the Department Of General Surgery, Bankura Sammilani Medical College \& Hospital, Bankura during the ensuing one year \& seven months will be included in this study as per inclusion and exclusion criteria's and will be graded as per severity assessment criteria. Early Laparoscopic Cholecystectomy and Delayed Elective Laparoscopic/open Cholecystectomy would be done accordingly and outcome will be evaluated.

\section{Plan for analysis of data}

The data of outcome will be analyzed and compared according to standard statistical analysis. A written informed consent was taken from all patients before their inclusion in the study. The study was approved by the ethical committee of the hospital.

Patients were randomly allocated to the two study groups using simple lots (25 in each group). Patients in one group underwent laparoscopic cholecystectomy while those in the other group underwent open cholecystectomy.

All the patients were kept nil by mouth overnight, prior to surgery and were given a dose of prophylactic antibiotic. All the patients were asked to evacuate bladder prior to surgery and a nasogastric tube was passed wherever required. All the surgeries were performed under general anesthesia.

Intra operative findings and post operative data were all recorded and analyzed, using simple statistical tests like Chi square test and Z-test, to compare the result.

\section{RESULTS}

On basis of duration in both of these surgical procedure, we found that laparoscopic cholecystectomy is slightly more time consuming procedure with average time of 120 mins in comparison with open cholecystectomy of average time 90 mins as shown in Figure 1.

In our study we have encountered intraoperative and postoperative complications in both of the groups as shown comparatively in Table 1 and 2. Bleeding in intraoperative period is more in laparoscopic procedure (8\%) as compared with open $(4 \%)$. As much as postoperative complications are concern laparoscopic procedure is with higher numbers as compared with open cholecystectomy. Out of 25 patients, 3 of them had postoperative bile leakage through drain $(12 \%)$ and 2 patients suffered from post cholecystectomy syndrome (8\%) as compared with open procedure where we find none of the patients with these complications, although surgical site infection was seen in open group ( $8 \%$ ) as compared with nil in laparoscopic group. Luckily we haven't seen any other intraoperative complications like bile duct injury, bowel injury etc. and postoperative complications like bleeding, jaundice and pulmonary complications in both groups during our study.

Comparison of the above data for intraoperative and postoperative complication in both of the groups by

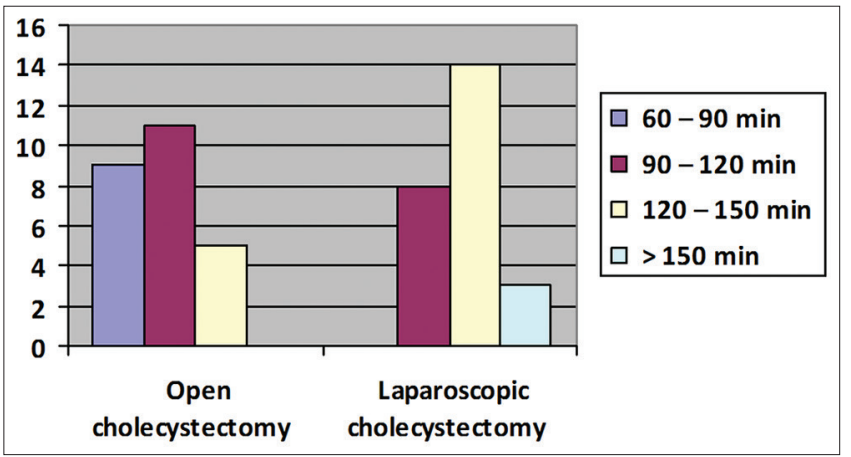

Figure 1: Duration of Procedure

For open method:

1. Minimum time: $70 \mathrm{~min}$

2.Maximum time: $130 \mathrm{~min}$

3.Average time: $90 \mathrm{~min}$

For laparoscopic method:

1.Minimum time: $105 \mathrm{~min}$

2.Maximum time: $170 \mathrm{~min}$

3.Average time: $120 \mathrm{~min}$ 
using Chi-Square test shows laparoscopic procedure is with higher complications $(14 \%)$ while open procedure is having comparatively less complications $(6 \%)$ shown in Table 3.

Duration of administration of antibiotics is greater in all aspects as minimum, maximum and average days in open cholecystectomy as compared to laparoscopic cholecystectomy shown in Figure 2 and 3.

In term of Post-operative analgesics, we have noticed that it may require to give analgesic to patients upto postoperative day- 6 in open cholecystectomy in comparison to laparoscopic procedure where analgesic may not needed from Post-operative day-4 or more as shown in Figure 4. This can be explainable because of larger incision and more tissue destruction in open cholecystectomy.

\begin{tabular}{lcc}
\multicolumn{3}{l}{ Table 1: Intraoperative complications } \\
\hline $\begin{array}{l}\text { Intraoperative } \\
\text { Complications }\end{array}$ & Open $\mathbf{C}(\mathbf{n = 2 5})$ & Lap ( $\mathbf{n = 2 5})$ \\
\hline Bleeding & 1 & 2 \\
Bile duct injury & 0 & 0 \\
Bowel injury & 0 & 0 \\
Others & 0 & 0 \\
Total & $1(4 \%)$ & $2(8 \%)$ \\
\hline
\end{tabular}

\begin{tabular}{lcc}
\multicolumn{2}{l}{ Table 2: Postoperative complications } & \\
Postoperative & $\begin{array}{c}\text { Open } \\
\text { (n=25) }\end{array}$ & $\begin{array}{c}\text { Lap } \\
\text { ( } \mathbf{n = 2 5})\end{array}$ \\
\hline Bomplications & 0 & 0 \\
Bile leak through drain & 0 & 3 \\
Wound infection & 2 & 0 \\
Jaundice & 0 & 0 \\
Post cholecystectomy syndrome & 0 & 2 \\
Pulmonary complications & 0 & 0 \\
Total & $2(8 \%)$ & $5(20 \%)$ \\
\hline
\end{tabular}

Patients start taking normal diet earlier in laparoscopic procedure as compared to open procedure. This resumption of normal diet normally from postoperative 3 or more day in open cholecystectomy group, where as in laparoscopic cholecystectomy group it is normally within 3 days and as early as within 48 Hours of procedure shown by Figure 5.

Due to much less size of incision, less complications, less requirement of antibiotics as well as analgesic and early resumption of normal diet results in lesser hospital stay. Figure 6 shows comparative result of hospital stay in laparoscopic and open cholecystectomy group. Average stay in hospital for open cholecystectomy is found to be 7 days and for laparoscopic cholecystectomy it is found to be 3 days.

While performing laparoscopic cholecystectomy it was converted to open method in 2 cases out of 25 (conversion rate $-8 \%$, Figure 7 ) patients due to the following reasons: 1. In one case there were plenty of thick adhesions between gallbladder and surrounding structures.

2. In another case there was excessive fat in the calot's triangle and cystic pedicle could not be identified.

Clinical details of patients subjected to laparoscopic or conventional open cholecystectomy are tabularized and shown in Table 4.

Values are mean +/- S.D, $\mathrm{P}<0.005$

\section{Statistical analysis}

The data are reported as the mean $+/$ - SD or the median ( $25^{\text {th }}$ to $75^{\text {th }}$ percentile), depending on their distribution. The differences in quantitative variables between groups were assessed by means of the unpaired test or the Mann-Whitney test. The chi-square test was used to assess

\section{Table 3: Comparison of complications}

\begin{tabular}{|c|c|c|c|}
\hline Complications [ $n=50$ ] & Open cholecystectomy & Laparoscopic cholecystectomy & Total \\
\hline Intra operative & 1 & 2 & 3 \\
\hline Post operative & 2 & 5 & 7 \\
\hline Total & $3[6 \%]$ & $7[14 \%]$ & 10 \\
\hline $\begin{array}{l}P=0.023 \text { significance } \\
\text { between the variables }\end{array}$ & & Chi-dist $=0.7822$ & \\
\hline
\end{tabular}

\section{Table 4: Clinical details of patients subjected to laparoscopic or conventional open cholecystectomy}

\begin{tabular}{lcc}
\hline Variables & Laparoscopic cholecystectomy $(\mathbf{n}=\mathbf{2 5})$ & Open cholecystectomy $(\mathbf{n}=\mathbf{2 5})$ \\
\hline Age (years) & $42.76+/-12.09$ & $39.12+/-13.79$ \\
Sex ratio (M/F) nos. & $7 / 18$ & $11 / 14$ \\
Duration of surgery (min) & $120+/-10.80$ & $90+/-13.84$ \\
Analgesic requirement (days) & $3.12+/-0.33$ & $6.08+/-0.40$ \\
Antibiotic requirement (days) & $4.28+/-0.46$ & $7.40+/-1.58$ \\
Complications (\%) [N=50] & $14 \%$ & $6 \%$ \\
Resumption of normal diet (days) & $3.16+/-0.85$ & $5.24+/-1.23$ \\
Post operative hospital stay (days) & $3.04+/-1.34$ & $7.76+/-1.23$ \\
\hline
\end{tabular}

Values are mean + / S.D, $P<0.005$ 


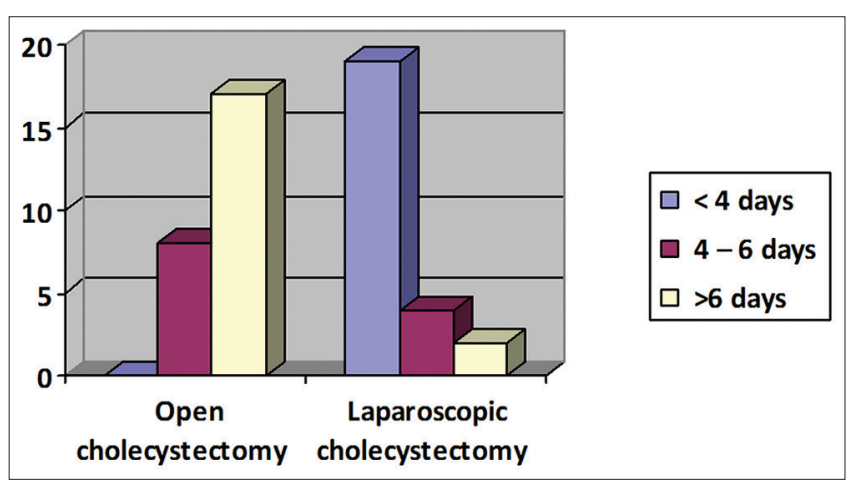

Figure 2: Duration of antibiotics administration For Open cholecystectomy:

1. Minimum - 5 Days

2. Maximum - 10 Days

For Laparoscopic Cholecystectomy :

1. Minimum - 3 Days

2. Maximum - 7 Days

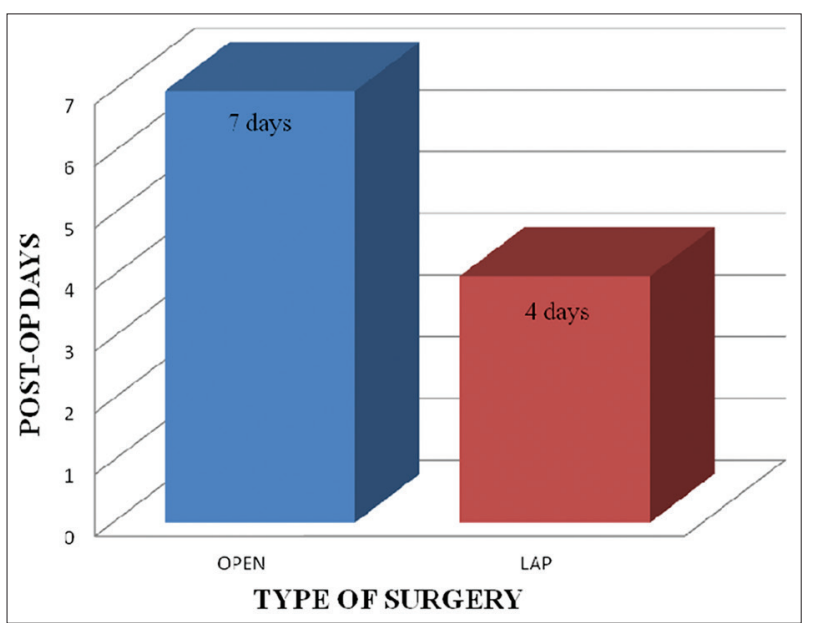

Figure 3: Average duration of antibiotic administration For open cholecystectomy average duration of antibiotics -7 Days For Laparoscopic cholecystectomy average duration of antibiotics -4 Days differences in categorical variables between groups. Values of $\mathrm{P}<0.005$ were considered to be significant. All statistical analyses were performed using the SAS software.

\section{DISCUSSION}

A study of 25 open cholecystectomy patients of which 18 female and 7 male patients were compared with that of 25 cases of laparoscopic cholecystectomy of which 14 female and 11 male patients.

In this study, the laparoscopic procedure was found to be associated with a longer operating time than open procedure (Median of 120 minutes for laparoscopic against 90 minutes for open method) (Figure-1). The more time required in $\mathrm{LC}$ was due to intra- operative gas leak, difficult adhesions, slippage of clips and delivery of gall bladder through the port site. This is comparable with that of studies of Trondsen and porte. ${ }^{1,2}$

As experience is gained, the operating time is decreased. This "learning curve" represents adapting to operating in the 2-D screen, becoming familiar with the instrumentation and becoming accustomed to the technique. The surgeon gets trained in dealing with challenging cases in the course of his/her learning curve.

In this study, there were no major complications and had several minor ones. There was no peri-operative mortality and no CBD injury. The complications observed were bile leak (OC-0, LC-3), blood loss (OC-1, LC-2), wound infection (OC-2, LC-0) and post cholecystectomy syndrome (OC-0, LC-2) which were found to be comparable in both the groups (Table 1,2 and Figure 2). Bile leak through drain tube in LC group was supposed to be from the gall bladder bed in liver due to minor

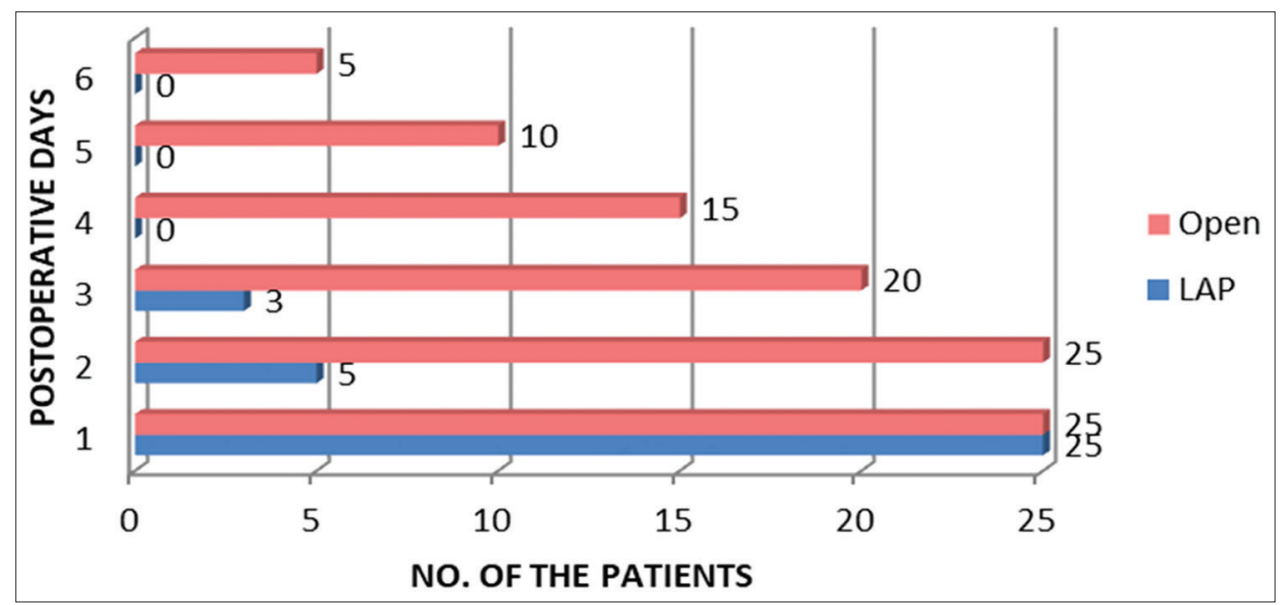

Figure 4: Post-operative analgesic requirement Maximum days of analgesic

Open method : 6 days

Lap method : 3 days 
injuries during dissection. All the three patients were treated conservatively, drains were kept for a period of 2 days and the leak subsided. The main reason for blood loss in LC group was from the gall bladder bed which eventually stopped on conservative management. There was no wound infection in LC group. 2 patients of OC group had wound infection, requiring regular dressing of the wounds, and the wounds healed over a period of 10 days. Wound infections were more commonly seen in the open group compared to laparoscopic group.

Harris ${ }^{3}$ in his study found similar results, Bile leak (LC-2\%, OC-1\%), bleeding requiring transfusion (LC-1\%, OC- $2 \%$ ) and wound infection rate (LC- $0 \%$, OC- $1 \%$ ). Other studies also reported similar results. ${ }^{4,2}$

The conversion from laparoscopic procedure to open procedure was necessary in 2 patients out of 25 . One patient required conversion due to difficult dissection in view of thick adhesions and the other due to excessive fat in calot's triangle. Conversion rate was $8 \%$ (figure-10). Conversion rate was also found to be higher in acute cases in other studies $(0-45 \%), 5,6,7$

The minimal antibiotic protocol used in our study was 5 days for open method against 3 days for laparoscopic method. Two of the open cases required antibiotics for a period of 10 days due to the wound infection, and two of the laparoscopic cases required antibiotics for a period of 7 days due to conversion. In our study, the antibiotic requirement was less in LC (median 4 days) to OC (median 7 days). This was due to the reduced size of the incision and lesser wound. This also reduced the need for post-operative antibiotics in the laparoscopy group (Figure 3 and 4).

Use of minimally invasive techniques in elective surgeries is associated with a reduced inflammatory stress response with improved pulmonary function and less hypoxia. ${ }^{8,9}$

The VAS(Visual Analogue Scale) was significantly less for LC group (median 2days) compared to (median 4days) for OC group; $\mathrm{p}<0.005$. Kumalso found a mean VAS score of $3.8 \mathrm{v} / \mathrm{s} 7.7$ between LC and OC. ${ }^{10}$ There was more pain and more analgesics were required in patients in the OC group, especially when the patient developed wound infection.

The pain duration (median 2 days for LC and median 4 days for OC patients) and the duration of analgesics used (median 2 days for $\mathrm{LC}$ and median 4 days for OC patients) also were significantly less in LC group patients (Figure 4). This was due to the lesser incision size in LC. Other studies have also shown similar results.2,11-15

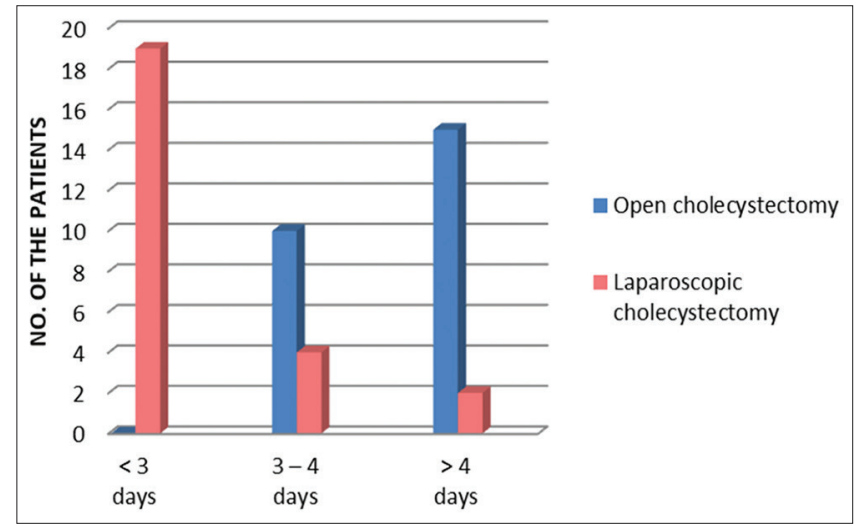

Figure 5: Resumption of normal diet

For open

Minimum - 3 days

Maximum -7 days

For lap

Minimum - 2 days

Maximum - 5 days

Average Post op resumption of normal diet for Open -5 Days

Average Post op resumption of normal diet for Lap -3 Days

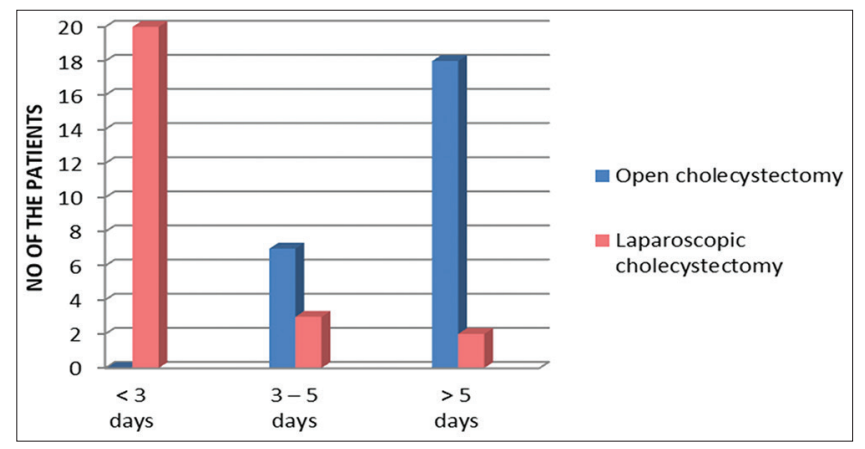

Figure 6: Hospital stay

For open

Minimum - 4 days

Maximum - 10 days

For lap

Minimum - 2 days

Maximum - 7 days

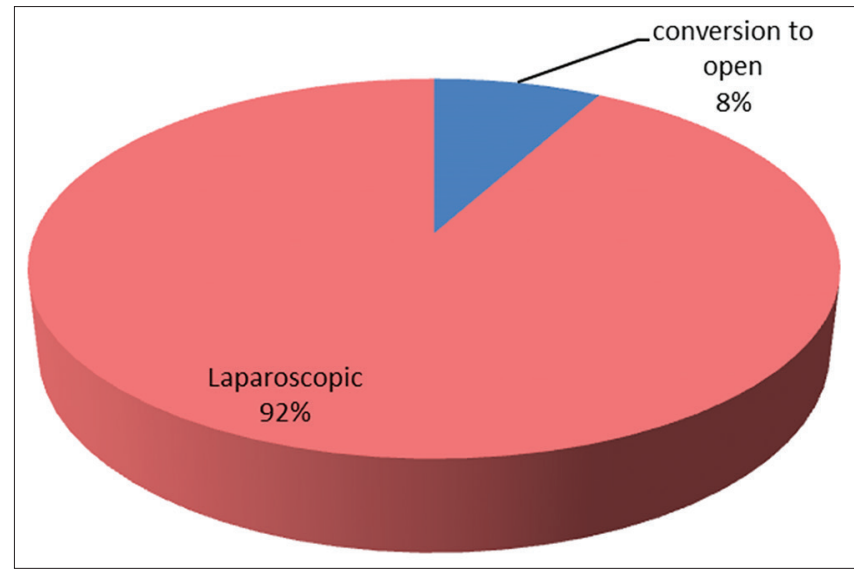

Figure 7: Conversion Rate 
The minimum resumption of normal diet for open method was 3 days compared to 2 days for laparoscopic method. The maximum resumption of normal diet for open method was 7 days due to wound infection, compared to 5 days for laparoscopic method following conversion. The mean resumption of normal diet for open method was 5 days compared to 3 days for laparoscopic method, suggesting the LC group returning to normal life earlier (Figure 5).

The two most beneficial aspects of LC are the short hospital stay and the rapid recovery.16

In this study, the median duration of hospital stay was 3 days for LC group and 7days for OC group (Figure 6). The difference was found to be statistically significant $(p<0.005)$. Hospital stay was more in OC group due to increased pain, wound infection, injectable antibiotics used and less mobilization due to pain. Trondsen, Porteand Lujan also found similar results. ${ }^{1,2,6}$ This was also confirmed in various other series. ${ }^{411,14,15,17,18}$

The OC group had larger wounds, which healed by primary intention with a single big scar. The LC group had port incisions of $<1.5 \mathrm{~cm}$, which healed by primary intention without much visible scar. Thus the cosmesis is the greatest advantage after lap cholecystectomy compared to open cholecystectomy.

\section{REFERENCES}

1. Trondsen $E$, Riertsen $O$, Anderson $O K$ and Kjaersgaard $P$. Laparoscopic and open cholecystectomy: A prospective randomized study. Eur J Surg 1993; 159(4):217-221.

2. Porte RJ and De Vries BC. Laparoscopic versus open cholecystectomy: a prospective matched- cohort study. HPB Surg 1996; 9(2): 71-75.

3. Harris BC. Retrospective comparison of outcome of 100 consecutive open cholecystectomies and 100 consecutive laparoscopic cholecystectomies. South Med J 1993; 86(9): 993-996.

4. Hardy KJ, Miller H, Fletcher DR, Jones RM, Shulkes A and McNeil JJ. An evaluation of laparoscopic versus open cholecystectomy. Med J Aug 1994; 160(2): 58-62.

5. Eldar S, Sabo E, Nash E, Abrahamson J and Matter I.
Laparoscopic versus opencholecystectomy in acute cholecystitis. Surg Laparoscopy Endoscopy 1997; 7(5):407-414.

6. Lujan JA, Parrilla P, Robles R, Marin P, Torralba JA and GarciaAyllon J. Laparoscopic versus open cholecystectomy in the treatment of acute cholecystitis: a prospective study. Arch Surg 1998; 133(2): 173-175.

7. Koperna T, Kisser M and Schulz F. Laparoscopic versus open treatment of patients with acute cholecystitis. Hepatogastroenterology 1999; 46(26): 753-757.

8. Williams MD, Sulentich SM and Murr PC. Laparoscopic cholecystectomy produces less post operative restriction of pulmonary function than open cholecystectomy. Surg Endosc 1993; 7(6): 489-492.

9. Farrow HC, Fletcher DR and Jones RM. The morbidity of surgical access: a study of open versus laparoscopic cholecystectomy. Aust NZJ Surg 1993; 63(12):952-954.

10. Kum CK, Wong CW, Goh PM and Ti TK. Comparative study of pain level and analgesic requirement after laparoscopic and open cholecystectomy. Surg Laparosc Endosc 1994; 4(2): 139-141.

11. Chan HS, Ha XF, Ooi PJ and Mack P. A prospective comparative study between conventional and laparoscopic cholecystectomy. Singapore Med J 1995; 36(4): 406-409.

12. Buanes $T$ and Mjaland $O$. Complications in laparoscopic and open cholecystectomy: a prospective comparative trial. Surg Laparosc Endosc 1996; 6(4): 266-272.

13. De Pouvourville G, Reibet-Reinhat N, Fendrick M, Houry $S$, Testas $\mathrm{P}$ and Huguier M. A prospective comparison of costs and morbidity of laparoscopic versus open cholecystectomy. Hepatogastroenterology 1997; 44(13): 35-39.

14. Hendolin HI, Paakonen ME, Alhava EM, Tarvainen R, Kempinen T and Lahtinen P. Laparoscopic or open cholecystectomy: a prospective randomized trial to compare postoperative pain, pulmonary function and stress response. Eur J Surg 2000 166(5): 394-399.

15. Schietroma M, Carlei F, Liakos C, Rossi M, Carloni A, Enang GN, et al. Laparoscopic versus open cholecystectomy: An analysis of clinical and financial aspects. Panminerva Med 2001; 43(4):239-242.

16. Attwood SE, Hill AD, Mealy $K$ and Stephens RB. A prospective comparison of laparoscopic cholecystectomy versus open cholecystectomy. Ann R Coll Surg Engl 1992; 74(6): 397-400.

17. Al Hadi FH, Chiedozi LC, Salem MM, George TV, Desouky M and Pasha SM. Comparison of laparoscopic and open cholecystectomy at Prince Abdulrahman Al Sudairy Hospital; Saudi Arabia. East Afr Med J 1998; 75(9): 536-539.

18. Capizzi FD, Fogli L, Brulatti M, Boschi S, Di Domenico M, Papa V, et al. Conversion rate in Laparoscopic cholecystectomy: evolution from 1993 and current state. J Laparoendosc Adv Surg Tech A 2003; 13(2): 89-91.

\footnotetext{
Authors Contribution:

MMN- Manuscript preparation, conceptualized the study, literature search, prepared the first draft of manuscript; SSK-Manuscript preparation, critical revision of manuscript, reviewed the literature; YS- Concept and design of study, literature search, collected data, statistically analysed and interpreted; PK- Literature search, helped in preparing first draft of the manuscript

Orcid ID:

Dr Shib Shankar Kuiri - ㄴ http://orcid.org/0000-0003-2212-6571

Dr Yash Sharma - ㄴ http://orcid.org/0000-0002-4038-5537

Source of Support: None, Conflict of Interest: None.
} 